\title{
Correlate of Post-natal care utilization in rural Ethiopia: An evidence from Secondary data analysis of Ethiopian Demographic Health survey 2016.
}

REKIKU Fikre Abebe ( $\square$ frekiku@yahoo.com )

Dilla university https://orcid.org/0000-0003-1324-1631

\section{Berhan Tsegaye Negash}

Hawassa University College of Medicine and Health Sciences

Zelalem Tenaw bogale

Hawassa University College of Medicine and Health Sciences

wegene Jemebere Beru

Hawassa University College of Medicine and Health Sciences

Getnet Kassahun Molla

Hawassa University College of Medicine and Health Sciences

Research article

Keywords: Postnatal care utilization,rural women, Ethiopia 2016.

Posted Date: November 7th, 2019

DOI: https://doi.org/10.21203/rs.2.16954/v1

License: (9) This work is licensed under a Creative Commons Attribution 4.0 International License.

Read Full License 


\section{Abstract}

Abstract Background: Postnatalcareutilizationis the most neglected care in Ethiopian,despite a large proportion of maternal and neonatal deaths occurs during postnatal period. Evidence suggested that utilization of postnatal care averts major complications of the fetus and mother.But,proportion of rular women utilization of postnatal care is low in Ethiopia. Information about prevalence and factors which determine utilization of postnatal care utlization in rular women in Ethiopia is mandatory for policy making, and program design to enhance its utilization. Objective: Theobjective of this study was to determine the prevalence of utilization of postnatal care and to identify its determinant factorsamong rural women who gave birth in the past five yearsbefore Ethiopian demographic health survey, in 2016. Method: This study utilized data from Ethiopian demographic health survey2016 for analysis. It is a national two stage, cross sectional study. It analyzed data for rural women who gave birth at least one time in the past five year before data survey time. Logistic regression was applied to identify explanatory variables associated with outcome variable. Adjusted odds ratio with $95 \%$ confidence interval was computed and P-value 0.05 was considered as statistically significant. Result:The prevalenceof postnatal care utilizationamong rural women was $11.4 \%$.Place of delivery[AOR=4.3, 95\% Cl, 1.4-5.2], ANCvisit [AOR=2.1, 95\% $\mathrm{Cl}, 1.1-3.9]$ and Women in the richest wealth quintile [AOR=2.97, 95\% $\mathrm{Cl}, 1.9-4.5]$ were factors associated with postnatal care service utilization among rural women in Ethiopia in 2016. Conclusion and recommendation: This study showed that prevalence of postnatal care utlization was low. Being in richest wealth quintile, history of ANC vist and place of delivery were positive predictors of postnatal care utlization among rural women. Regardless of proven strategies utilized to maximize utilization of postnatal care utlization by the government of Ethiopia, this study showed that prevalence is low in rural areas. Therefore, community awareness creation, increasing institutional coverage by expanding maternity waiting area and besides, the government should design and implement income increasing package among rural women.

\section{Introduction}

The postnatal period is a vitalstage in the lives of mothers and newborn babies. Most maternal and infant deaths occur during this time[1]. The post-natal period is the most eventfully period in which delay to intervene at the time of complication during this period will result in short term effectson lifelong disability and death[2].Prompt action at the time of complication will decrease adverse effects both for fetuses and mothers [3], [4], [5].

In 2017, about 295000 women died during and following pregnancy and childbirth. The vast majority of these deaths (94\%) occurred in low-resource settings, and Sub-Saharan Africa accounts two-third of maternal death followed by South Asia accounts one-fifth[6]. Despite this fact sub-Saharan region achieved successes and decrease $40 \%$ of MMR since 2000 . However, Maternal deaths in some areas of the world reflects inequalities The MMR in low-income countries in 2017 is 462 per 100000 live births versus 11 per 100000 live births in high-income countries and the risk of maternal mortality is highest for 
adolescent girls under 15 years old and complications in pregnancy and childbirth are higher among adolescent girls age 10-19 [7], [8].

The fact that 18 million women in Africa currentlydo not give birth in a health facility poses challenges forplanning and implementing postnatal care for women andtheir newborns. Despite its importance, this period is generally themost neglected in developing countries and most mothers andnewborn babies do not receive postnatal care services from askilled health care provider during the critical first few daysafter delivery[9], [10].

Postnatal utilization in Ethiopian has very slow progress.A large proportion of maternal and neonatal deaths occur during the first 24 hours after delivery. This period is most critical for both mother and neonatal survival, and the most vital time for recognizing problems and initiating early interventions to avoid complications[11, 12]. However, postnatal care utilization continues to have the lowest coverage, according to 2016 EDHS with only $17 \%$ of the women utilizing postnatal care.

Forty-five percent of urban women received a postnatal check-up within 2 days compared to $13 \%$ ofpostnatal care in rural: Seventeen percent of women and $13 \%$ of newborns received a postnatal check within the first 2 days of birth[13].Prevalence and determinant factors of postnatal careare mandatory for effectively design policies and programs about at national level for rural women. Therefore, the main aim of this study is to assess prevalence and determinant factors of postnatal care utilization among rural women.

\section{Methods And Materials}

\section{Study area and period}

Ethiopia is one of the developing countries which is found in East Africa. Administratively, it is divided into nine regional states and two city administrations. Each region is divided into zones, and zones are further sub-divided into districts. There are a total of 817 districts throughout the country. Districts are even sub-divided into Kebeles (the lowest administrative units). There were 16,253 Kebeles. The total population of the nation reached 94.3 million in 2017. Nearly, $80 \%$ of Ethiopian population lives in rural areas. The average size of each household is estimated to be 4.6 individuals. It was conducted from January, 18 to June 27,2016 .

\section{Study variables}

In this study the dependent variable was postnatal care utlization. It has binary outcomes. A total of 5681 births and related information were reported within five years preceding survey and were included in this study. Analysis was restricted to these 5681 last births to minimize recalling bas.

Rural women were asked as 'did you utilized postnatal care at least once or not?'. They answered as 'yes' or 'no'. The response 'yes' was coded as ' 1 ' and the response 'No' was coded as ' 0 '. Further details of sampling, questionnaire and procedure can be found in the publicly available survey 
report[13].Independent variables were categorized into socio-demographic characteristics and reproductive health characteristics. Variables like age and family size was recorded as continues variable and was categorized into three categories, ethnicity was categorized into six parts according to their relative proportion of population. But, there are more than 85 ethnicities in Ethiopia. Women's occupational status was merged into five main occupations. However, more than nine occupations were listed in the data. place of residence, respondent's educational status, respondent's husband educational status, religion, ethnicity, marital status and wealth index and frequency of listening radio.Moreover, reproductive health characteristics consist of age at first pregnancy, number of birth, number of antenatal visit, current pregnancy.

\section{Operational definition}

Wealth index was constructed using principal components analysison household asset data. Individuals were classified into five wealth quintiles (poorest, poorer, medium, richer and richest). It included ownership of selected household assets, size of agricultural land, quantity of livestock and materials used for house construction(Rutstein SO: The DHS Wealth Index: Approaches for rural and urban areas, 2008).

\section{Sample size and sampling procedures}

This study used two stage, stratified and cluster sampling technique to select households. Ethiopian demographic health survey 2016 has utilized 84,915 list of enumeration areas as a sampling frame to samples. An enumeration area is a geographic area which contains one hundred-eighty- one (181) households. The sampling frame contains information about the enumerating area location, type of residence, and estimated number of households.Each region was stratified into urban and rural areas, yielding 21 strata. In the first stage, a total of 645 enumeration area (EAs). These were divided into rural and urban (202 EAs in urban and 443 EAs in rural areas). They were selected based on probability proportional to the sizeof EA.

In the second stage, a new sampling frame was created which consist of lists of households for the selected strata. Then a fixed number of 28 households per cluster were selected with an equal probability using systematic random sampling technique from the new sampling frame. All women in reproductive age group lived in selected households were eligible for interview. A total of 18,008 households were selected for this study. In the interviewed households, a total of 7590 women gave birth five years back from survey data collection time were included for analysis in this study. All of them completed the interview, yielding a response rate of $100 \%$.

\section{Study design and population}

This study is the secondary data analysis of Ethiopian demographic health survey 2016.It is a cross sectional study which was conducted over five and half months' period. All reproductive age women in 
Ethiopia who gave birth five years before EDHS 2016 data collection period were target(source) population of this study.

Study population of the current study included all women who gave birth five years beforeEDHS 2016 data collection time, lived in the selected strata, and presented during data collection time.

\section{Data collection and analysis}

EDHS 2016 used nationally validated standard questionnaire. Pretest was conducted from October 1-28, 2015. The questionnaire was prepared first in Amharic, Oromiffa and Tigrigna which are the three common local language spoken by majorities of Ethiopian population respectively. Then, it was translated into English language. Finally, it was translated back to local languages for consistency. Though the questionnaire consists of five different parts, we used data collected from women of reproductive age group for this analysis. Fieldwork was carried out by 33 field teams. Each consisting of one team supervisor, one field editor, three female interviewers, one male interviewer, two biomarker technicians, and one driver. In addition, 28 quality controllers were dispatched during data collection.Complex sample analysis was performed using SPSS version 22 statistical software to account for the multistage cluster study design. Analysis was carried out based on the weighted count. Sample weight was an eight-digit variable with six implied decimal places and was divided by $1,000,000$ before applying the weighting factor. Multivariable logistic regression was used to identify independent predictors of caesarean section delivery. Results were presented in the form of odds ratios, and $95 \%$ confidence intervals. Statistical significance was set at a p-value of 0.05 .

\section{Results}

\section{Sample socio-demographic characteristics and postnatal care utlization}

Out of the 5681 rural women who gave birth in the last five years who answered question about postnatal care sevice $11.4 \%$ of rular women utilizatied postnatal care in Ethiopia.Table one showed that sociodemographic characteristics of study participants who had at least one birth in the past five years, before Ethiopian demographic and health survey 2016, data collection timeThemeanage of study participants was $29.3+7$ years. The majority of $93.8 \%$ women were married. $70.1 \%$ of respondents had no formal education and $80 \%$ women not listening radio at all .In addition, more than half (58.4\%) of study participants had no formal work. Besides, majorities 3540(62.3\%) of the subjects lived in household size of more than five in this study see table 1.

Among respondents $93.2 \%$ of women's current pregnancy was unwanted.Majorities $61 \%$ of the women had less than four children. $45.8 \%$ of women were using contraceptives Those women who delivered at health institution accounted of $1533(27 \%)$. Study subjects who were pregnant at the time of study reached to $671(11.8 \%)$. Majorities of the study participants $4321(76.1 \%)$ had no pregnancy complications see table 2. 


\section{Determinants of postnatal utilization among rural women}

In this study, frequency of listing radio, family size, wealth quintile, place of delivery,told about pregnancy complication and husband occupation were factors significantly associated with postnatal utilization in rural womenin a bivariate logistic regression model. However three variables were associated statistically in AOR model. Place of delivery4.3 times [AOR=4.3, 95\% $\mathrm{Cl}, 1.4-5.2]$ more likely to use post-natal service than their counterparts. ANC was 2.1 times $[A O R=2.1,95 \% \mathrm{Cl}, 1.1-3.9]$ more likely to use postnatal service than their counterpart. Women in the richest wealth quintile were 2.97 times [AOR=2.97, 95\% $\mathrm{Cl}, 1.9-4.5]$ more likely to use post-natal service than their counterparts see table 3.

\section{Discussion}

The prevalenceof post-natal utilizationin rural women was $11.4 \%$. This finding is lower than the national prevalence of postnatal utilization in Ethiopiait was 17\%[13]. The possible explanation for thisdue to poor accessto road to facilities and most women give birth at home. This finding was lower than study conducted in Rwanda 12.8\% [14], Nigeria 16.9\% [15], Bangladesh 73.8\% [16],India 36.6\%[17] and Myanmar 83.68\% [18]The possible rationale for this difference might be due to women's sociodemographic difference, low level of awareness Moreover, culturally embedded male dominance in rural Ethiopia reduce women's decision ability to utilize maternal health services, in rural Ethiopia. Women in richest wealth quintile were 2.97 times more likely to utilized postnatal service than the poorest one. This finding isconsistent with a study in Nepal and Rwanda[14], [19].The possible rationale might be that poor women in rural Ethiopia could not afford indirect costs for delivery even if the service is free in public health institutions. Poor women are more likely to be less educated, less autonomous and less access to health services.

Place of delivery 4.3 times [AOR=4.3, 95\% Cl, 1.4-9.2] more likely to use post-natal service than their counterparts. This finding is consistent with the study in Nepal[19], Tanzania[20], and Rwanda[14].The possible rationale could be if women delivered at health facilities the knowledge about the importance of the service could be clear for women and the facilities could create a link with health post to get the service. Women with ANC Visit were 2.1times [AOR=2.1, 95\% Cl, 1.1-3.9] more likely to use postnatal service than their counterparts.

This finding is consistent with study in Nigeria[15].The possible reason for this might be that women could get education and the approaches of women-friendly service of providers create an opportunity for the women to give birth at institution.

\section{Conclusion and public health implication}

Being in richest wealth quintile, place of delivery and ANC vist were positive predictors of postnatal care utlization among rural women. Results from this study point to a combination of community and facilitybased interventions as feasible measures to reach poor and home delivery mothers in rural Ethiopia. 
Community awareness creation and strong legal policies should be drafted towards home delivery among rural women in Ethiopia. Besides, the government should design and implement income increasing package among rural women in Ethiopia. These should be the focus of future strategy to effectively utilize postnatal care utilization .

\section{Strength and Limitation}

This study has many strengths. These include a national wide study with large sample size and high response rate. Moreover, demographic and health surveys are internationally validated and nation. adapted surveys. Therefore, the current findings are generalizable to rural women of the entire country. The study design and sampling follow standard procedure which makes possible to yield accurate and reliable estimate. Nevertheless, the current study has several limitations. This study could create recall bias. Nevertheless, this bias is not considered problematic since this study included only women giving birth within five years preceding the survey. Moreover, this secondary data analysis of Ethiopian demographic and health and survey could not provide variables associated with pregnancy complications.

\section{Abbreviations}

AOR_-_-_-Adjusted odds ratio

EDHS-_-_-Ethiopia demographic and health survey

MMR_-_-_Maternal mortality ration

\section{Declarations}

\section{Ethics approval and consent to participate}

A written ethical clearance was obtained from the Institutional Review Board at the College of Medicine and Health Sciences of Hawassa University, Hawassa, Ethiopia.

\section{Acknowledgment}

We are grateful to the Ethiopia static bureau for delivering us the data and senior staff for technical support.

\section{Author contribution}

RF Design the study, Proposal development, data analysis and manuscript preparation

BT,ZT,WJ and GK participated on data analysis and manuscript preparation 


\section{Funding}

No source of funding to carry out for this research.

\section{Availability of data and materials}

All data generated or analyzed during this study were included in this published article and its supplementary information files

\section{Consent to publish}

Not applicable

\section{Competing interest}

No competing interest

\section{References}

1.Lawn, J., M. Kinney, and H.J.L. Blencowe, Every newborn, an executive summary for the lancet series. 2014. 384(9938): p. 1-8.

2.Organization, W.H., Postpartum care of the mother and newborn: a practical guide: report of a technical working group. 1998, Geneva: World Health Organization.

3.Organization, W.H., WHO technical consultation on postpartum and postnatal care. 2010, Geneva: World Health Organization.

4.Lawn, J.E., et al., 4 million neonatal deaths: when? Where? Why? 2005. 365(9462): p. 891-900.

5.Warren, C., et al., Opportunities for Africa's newborns."Postnatal care." 2006.

6.Organization, W.H., Trends in maternal mortality 2000 to 2017: estimates by WHO, UNICEF, UNFPA, World Bank Group and the United Nations Population Division: executive summary. 2019, World Health Organization.

7.Ganchimeg, T., et al., Pregnancy and childbirth outcomes among adolescent mothers: a W orld H ealth O rganization multicountry study. 2014. 121: p. 40-48.

8.Althabe, F., et al., Adverse maternal and perinatal outcomes in adolescent pregnancies: The Global Network's Maternal Newborn Health Registry study. 2015. 12(2): p. S8.

9.UNICEF, W., UN and World bank, Level and trends of child mortality. 2015.

10.DiBari, J.N., et al., Use of postpartum care: predictors and barriers. 2014. 2014. 
11.Organization, W.H. WHO recommendations on postnatal care of the mother and newborn. 2014; Available from: https://www.who.int/maternal_child_adolescent/documents/postnatal-carerecommendations/en/.

12.WHO, Technical consultation on postpartum and postnatal

care. 2013: Geneva, Switzerland.

13.Ethiopian demographic and health survey 2016. 2016: Ethiopia.

14.Bernard N. Rwabufigiri, J.M., Dana R. Thomson1, Bethany L. Hedt-Gautier and Jean Paul S. Semasaka, Factors associated with postnatal care utilization in Rwanda: A secondary analysis of 2010 Demographic and Health Survey data. BMc pregnancy and childbirth, 2016. 16(122).

15.Idris Usman Takai, H.D.D., Mohammed Bukar, Bala Mohammed Audu, Aliyu Salihu and Kwayabura, Factors responsible for under-utilization of postnatal care services in Maiduguri, north-eastern Nigeria. Sahel Medical Journal, 2015. 18.

16.S K Nayan, N.B., M R Abid, S Rahman, A K Rajib, N Farzana and M L Nahar, Northern International Medical College Journal. Utilization of Postnatal Care Services among the Rural Women in Bangladesh, 2017. 8: p. 208-212.

17.Arvind sharma, p.s.t., pradeep kumar kasar, rajesh tiwari and , richa sharma, utilization of post natal care in tribal area of madhya pradesh. international journal of medical science and public health, 2014

18.Mon, A., et al., Utilization of full postnatal care services among rural Myanmar women and its determinants: a cross-sectional study [version 1; peer review: 3 approved]. 2018. 7(1167).

19.Vishnu Khanal, M.A., Rajendra Karkee and Tania Gavidia, Factors associated with the utilisation of postnatal care services among the mothers of Nepal: analysis of Nepal Demographic and Health Survey 2011. BMC women health, 2014. 14 p. 19.

20.Almamy M. Kanté, C.E.C., Anna M. Larsen, Amon Exavery, Kassimu Tani and James F. Phillips Factors associated with compliance with the recommended frequency of postnatal care services in three rural districts of Tanzania. BMC Pregnancy and Childbirth, 2015. 15: p. 341.

\section{Tables}

Table 1: Socio-demographic characteristics of study participants who utilized postnatal service in rural women, EDHS 2016. 


\begin{tabular}{|c|c|c|c|}
\hline Variables & Category & Frequency & Percentage \\
\hline Age & $\begin{array}{l}15-24 \\
25-34 \\
\geq 35\end{array}$ & $\begin{array}{l}1761 \\
2138 \\
1782\end{array}$ & $\begin{array}{l}30.3 \\
37.6 \\
31.4\end{array}$ \\
\hline Ethnicity & $\begin{array}{l}\text { Amhara } \\
\text { Oromo } \\
\text { Tigre } \\
\text { Afar }\end{array}$ & $\begin{array}{l}855 \\
1399 \\
631 \\
551\end{array}$ & $\begin{array}{l}15 \\
24.5 \\
11.1 \\
9.7\end{array}$ \\
\hline Religion & $\begin{array}{l}\text { Orthodox } \\
\text { Protestant } \\
\text { Muslim } \\
\text { Catholic }\end{array}$ & $\begin{array}{r}1654 \\
1124 \\
2760 \\
37\end{array}$ & $\begin{array}{l}32.9 \\
20.6 \\
44.5 \\
2.00\end{array}$ \\
\hline Marital status & $\begin{array}{l}\text { Single } \\
\text { Married } \\
\text { Widowed } \\
\text { Divorced }\end{array}$ & $\begin{array}{r}82 \\
5326 \\
194 \\
79\end{array}$ & $\begin{array}{r}1.4 \\
93.8 \\
3.4 \\
10.9\end{array}$ \\
\hline Educational status & $\begin{array}{l}\text { No education } \\
\text { Primary } \\
\text { Secondary } \\
\text { Higher }\end{array}$ & $\begin{array}{r}3983 \\
1426 \\
223 \\
49 \\
\end{array}$ & $\begin{array}{r}70.1 \\
25.1 \\
3.9 \\
0.9 \\
\end{array}$ \\
\hline Wealth index & $\begin{array}{l}\text { Poorest } \\
\text { Poor } \\
\text { Middle } \\
\text { Rich } \\
\text { Richest }\end{array}$ & $\begin{array}{r}2362 \\
1149 \\
998 \\
860 \\
312 \\
\end{array}$ & $\begin{array}{r}41.6 \\
20.2 \\
17.6 \\
15.1 \\
5.1 \\
\end{array}$ \\
\hline Family size & $\begin{array}{l}1-4 \\
5-9\end{array}$ & $\begin{array}{l}1755 \\
3185\end{array}$ & $\begin{array}{r}31 \\
56.1\end{array}$ \\
\hline
\end{tabular}




\begin{tabular}{|c|c|c|c|}
\hline & $>=10$ & 741 & 13 \\
\hline Frequency of listening radio & $\begin{array}{l}\text { Not at all } \\
\text { Less than once a week } \\
\text { At least once a week }\end{array}$ & $\begin{array}{r}4546 \\
602 \\
533\end{array}$ & $\begin{array}{r}80 \\
10.6 \\
9.4\end{array}$ \\
\hline
\end{tabular}

Table 2:Reproductive health characteristics of study participants who utilized postnatal service in rural women, EDHS 2016.

\begin{tabular}{|l|l|l|l|}
\hline Variables & Category & Frequency & Percentage \\
\hline \multirow{2}{*}{$\begin{array}{l}\text { Current } \\
\text { Pregnancy }\end{array}$} & Yes & 671 & 6.8 \\
\cline { 2 - 4 } \multirow{2}{*}{$\begin{array}{l}\text { Ever had terminated } \\
\text { pregnancy }\end{array}$} & No & 5010 & 93.2 \\
\hline \multirow{2}{*}{ Total number of birth } & Yes & 498 & 7.6 \\
\cline { 2 - 4 } & $1-4$ & 5183 & 92.4 \\
\hline \multirow{2}{*}{\begin{tabular}{l} 
Current use contraceptive \\
\cline { 2 - 4 }
\end{tabular}} & $>=5$ & 1755 & 31 \\
\hline \multirow{2}{*}{$\begin{array}{l}\text { Place of } \\
\text { delivery }\end{array}$} & Yes & 3926 & 69 \\
\hline \multirow{2}{*}{$\begin{array}{l}\text { Told about pregnancy } \\
\text { complication }\end{array}$} & No & 2560 & 45 \\
\cline { 2 - 4 } & Institution & 3121 & 55 \\
\hline \multirow{2}{*}{} & Yes & 4148 & 79.1 \\
\cline { 2 - 4 } & No & 1533 & 20.9 \\
\hline
\end{tabular}

Table 3:Factors associated with postnatal utilization of rural women by multivariable logistic regression, EDHS 2016. 


\begin{tabular}{|c|c|c|c|c|c|}
\hline \multirow[t]{2}{*}{ Variables } & \multirow[t]{2}{*}{ Category } & \multicolumn{2}{|c|}{ Post-natal utilization } & \multirow[t]{2}{*}{ COR[95\%CI] } & \multirow[t]{2}{*}{ AOR[95\%CI] } \\
\hline & & Yes & No & & \\
\hline \multirow[t]{2}{*}{ Place of delivery } & Home & 4047 & 101 & 1 & \\
\hline & Institution & 1489 & 44 & $4.3[1.1-7.1]$ & $4.3[1.4-5.2]^{* *}$ \\
\hline \multirow[t]{5}{*}{ Wealth index } & Poorest & 1901 & 32 & 1 & \\
\hline & Poorer & 1242 & 9 & $1.1[0.4-2.2]$ & $1.1[0.2-2.0]$ \\
\hline & Middle & 1354 & 28 & $1.3[0.5-6.2] *$ & $1.3[0.3-5.5]$ \\
\hline & Richer & 1321 & 12 & $1.8[0.1-3.1]^{*}$ & $1.6[0.3-6.1]$ \\
\hline & Richest & 1613 & 78 & 2.97[2.4-11.6]* & $2.97[1.9-4.5]^{* *}$ \\
\hline \multirow[t]{2}{*}{ ANC visit } & No & 3286 & 69 & 1 & 1 \\
\hline & Yes & 4102 & 132 & $2.1[1.3-4.1]^{*}$ & $2.1[1.1-3.9]^{* *}$ \\
\hline
\end{tabular}

